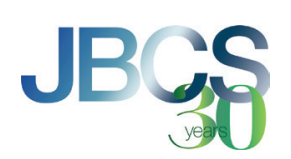

http://dx.doi.org/10.21577/0103-5053.20190101

\title{
Benzodioxol Group Driving Supramolecular Arrangement of Two Tri-Methoxy Chalcones onto Beta-Secretase 1 Enzyme Active Site
}

\author{
Vitor S. Duarte, ${ }^{a}$ Jean M. F. Custodio, ${ }^{b}$ Murilo M. dos Anjos, ${ }^{b}$ Nádia M. Borges, ${ }^{a}$ \\ Guilherme R. Oliveira ${ }^{b}$ and Hamilton B. Napolitano ${ }^{\circledR} * a$ \\ ${ }^{a}$ Campus de Ciências Exatas e Tecnológicas, Universidade Estadual de Goiás, \\ 75132-903 Anápolis-GO, Brazil

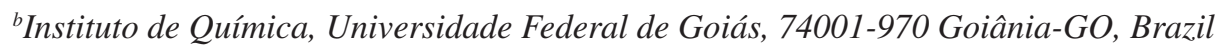

\begin{abstract}
Chalcones are compounds with wide interesting biological activities including Alzheimer's disease. A comparative study was performed between the chalcones (E)-1-(2-aminophenyl)3-(3,4,5-trimethoxyphenyl)prop-2-en-1-one and 1-(6-amino-1,3-benzodioxol-5-yl)3-(3,4,5-trimethoxyphenyl)prop-2-en-1-one regarding the influence of benzodioxol group on their molecular conformations. The first chalcone was neutralized with dilute hydrochloric acid, while solid of the second was filtered and recrystallized from ethanol, both on centrosymmetric space group $\mathrm{P} 2_{1} / \mathrm{c}$. Their molecular packing were evaluated by Hirshfeld surfaces, and both frontier molecular orbitals and molecular electrostatic potential (MEP) map were carried out by density functional theory (DFT) calculations. The compounds are stabilized by $\mathrm{C}-\mathrm{H} \cdots \mathrm{O}$ and $\mathrm{C}-\mathrm{H} \cdots \pi$ interactions, as observed on MEP map, while the HOMO-LUMO gap indicated the conformational stability. The pharmacophore mapping approach was carried out for the identification of potential target candidates and then, further molecular docking analysis targeting the beta-secretase 1 (BACE-1) protein as a tactic to develop potential AD inhibitors, was performed. The AutoDock Vina score in redocking result for $2 \mathrm{OHQ}$ is -7.4 and $-7.6 \mathrm{kcal} \mathrm{mol}^{-1}$. Additionally, the docking results for compounds inside the active site of the 2OHQ structure showed that both compounds bound to the BACE-1 active site with AutoDock Vina score of $-6.0 \mathrm{kcal} \mathrm{mol}^{-1}$.
\end{abstract}

Keywords: tri-methoxy chalcones, Hirshfeld surfaces, molecular docking, DFT

\section{Introduction}

Chalcones are chemical compounds often obtained in various types of plants or synthetic sources,${ }^{1-3}$ usually derived from the condensation of aromatic aldehyde with acetophenones in the presence of catalyst, being the principal precursors for the biosynthesis of flavonoids and isoflavonoids. ${ }^{1,2,4}$ Basically, their structures are formed by two aromatic rings bounded by an open chain formed by an olefin portion and an $\alpha, \beta$-unsaturated carbonyl system. ${ }^{4,5}$ This compound class has attracted interest due to broad biological activities, such as anti-inflammatory, anti-fungal, anti-cancer, antibacterial, antiprotozal, anti-consulvant, anti-oxidant, anti-malarial, cytotoxic, insecticidal and treatment of Alzheimer's disease. ${ }^{6-12}$

Since many biological activities are attributed to chalcones, the understanding on how substituents affect their

*e-mail: hbnapolitano@gmail.com conformation and supramolecular arrangement is important because such activities are related to the molecular structure. For instance, some articles ${ }^{13-15}$ show that the structure-activity relationship (SAR) for different substituents can affect the biological activity.In this sense, chalcones containing the benzodioxol group were evaluated against bacteria and fungi, ${ }^{9}$ Cruzain from Trypanosoma cruzi, antihyperglycemic ${ }^{16}$ and larvicidal activity. ${ }^{17}$ Furthermore, several enzymatic studies have demonstrated inhibitory activity of chalcone derivatives against monoamine oxidase- $\mathrm{B}^{16,17}$ and beta-secretase 1 (BACE-1). ${ }^{18}$ In this context, molecular docking studies can be used on investigations of a molecular target. Inverse virtual screening (IVS) is a technique to find the molecular targets, ${ }^{19}$ it is applied to several compounds and plays an important role in identifying potential bioactive substances. Additionally, IVS is useful to evaluate molecular targets in the context of drug discovery, e.g., of study on antitumor targets,${ }^{20}$ besides a comprehensive investigation about chemical universe with the proteome. ${ }^{21}$ 
In this article, we report a comparative analysis between chalcones ( $E)$-1-(2-aminophenyl)3-(3,4,5-trimethoxy phenyl)prop-2-en-1-one), $\mathrm{C}_{18} \mathrm{H}_{19} \mathrm{NO}_{4}$, (I) and (1-(6-amino-1,3-benzodioxol-5-yl)3-(3,4,5-trimethoxyphenyl)prop-2-en-1-one), $\mathrm{C}_{19} \mathrm{H}_{19} \mathrm{NO}_{6}$, (II). ${ }^{22}$ The supramolecular arrangements of compounds I and II were analyzed and characterized from Hirshfeld surfaces (HS), and theoretical calculations were performed to explain the chemical stability. Also, the potential target candidates through pharmacophore mapping for both chalcones were predicted and the beta-secretase 1 structure was used for docking studies.

\section{Experimental}

\section{Synthesis and crystallization}

Compound I was synthesized based on the procedure described by Bandgar et al. ${ }^{23}$ In a balloon it was added $10 \mathrm{~mL}$ of ethanol and catalytic amount of $\mathrm{NaOH}(67 \mathrm{mg})$. The system was stirred until the solution became homogeneous. Next, it was added $o$-aminoacetophenone (1 mmol, $0.135 \mathrm{mg}$ ) and 3,4,5-trimethoxybenzaldehyde (1 mmol, $0.196 \mathrm{mg}$ ) (Figure 1). The reaction was stirred at room temperature for $20 \mathrm{~h}$, followed by thin layer chromatography. The solution was neutralized with dilute hydrochloric acid, occurring at precipitation of a solid. The solid of II was filtered and recrystallized from ethanol.

\section{Single crystal X-ray analysis}

The crystal of compound I was measured on a Bruker D8 VENTURE system at room temperature and a $\mathrm{CuK}_{\alpha}$ microfocus sealed tube $(\lambda=1.54178 \AA)$. The structure was solved and refined using the Bruker SHELXTL software package, ${ }^{24}$ using the space group $\mathrm{P}_{1} / \mathrm{c}$. The final anisotropic full-matrix least-squares refinement on $\mathrm{F}^{2}$ with 218 variables converged at $\mathrm{R} 1=0.0473$, for the observed data and $\mathrm{wR} 2=0.1453 \%$ for all data and the goodness-of-fit 1.060. The crystallographic information files of compound $\mathbf{I}$ were deposited in the Cambridge Crystallographyc Data Centre (CCDC) ${ }^{25}$ under the code 1866290 (Supplementary Information section). The data of compound II were obtained from CCDC with code 180169 (Supplementary
Information section). ${ }^{22}$ The crystallographic information of compounds I and II are shown in Table 1 for comparison.

Table 1. Crystallographic data and structure refinement for compounds I and II

\begin{tabular}{lcc}
\hline Parameter & $\mathrm{C}_{18} \mathrm{H}_{19} \mathrm{NO}_{4}(\mathbf{I})$ & $\mathrm{C}_{19} \mathrm{H}_{19} \mathrm{NO}_{6}(\mathbf{I I})$ \\
\hline Formula weight / $\left(\mathrm{g} \mathrm{mol}^{-1}\right)$ & 313.35 & 357.35 \\
Temperature / $\mathrm{K}$ & $293(2)$ & $150(1)$ \\
Wavelength / $\AA$ & 1.54178 & 0.71073 \\
Crystal size / mm & $0.07 \times 0.14 \times 0.26$ & $0.4 \times 0.1 \times 0.1$ \\
Crystal habit & yellow block & orange block \\
Crystal system & monoclinic & monoclinic \\
Space group & $\mathrm{P} 2_{1} / \mathrm{c}$ & $\mathrm{P} 2_{1} / \mathrm{c}$ \\
$a / \AA$ & $12.7264(3)$ & $23.5477(4)$ \\
$b / \AA$ & $8.6478(2)$ & $4.9605(1)$ \\
$c / \AA$ & $15.2955(4)$ & $14.2556(8)$ \\
$\alpha, \gamma /$ degree & 90 & 90 \\
$\beta /$ degree & $103.8320(10)$ & $100.702(1)$ \\
Volume / ${ }^{3}$ & $1634.54(7)$ & $1636.21(10)$ \\
$\mathrm{Z}$ & 4 & 4 \\
Density (calculated) / $\left(\mathrm{mg} \mathrm{m}^{-3}\right)$ & 1.273 & 1.451 \\
Absorption coefficien / mm & -1 \\
$\mathrm{~F}(000)$ & 0.739 & 0.109 \\
Refinement method & 664 & 752 \\
& full-matrix least- & full-matrix least- \\
Goodness-of-fit $(\mathrm{S})$ & squares on $\mathrm{F}^{2}$ & squares on F \\
Final R indices & 1.060 & 1.030 \\
$(\mathrm{I}>2 \sigma(\mathrm{I}))$ & 0.0473 & 0.044 \\
\hline
\end{tabular}

$\overline{a-c}$ and $\alpha-\gamma$ : unit cell parameters; Z: formula unit per unit cell; $\mathrm{F}(000)$ : structure factor in the zeroth-order case; $\mathrm{F}^{2}$ : squared structure factor.

\section{Hirshfeld surface analysis}

The Hirshfeld surface (HS) is a graphical tool based on the electronic density of molecules related to their chemical environment, providing both interpretation and quantification of the intermolecular interactions that occur in a molecule. ${ }^{26}$ These surfaces can be understood as a space of partition in the crystal with regions where there is distribution of electrons of a sum of spherical atoms. ${ }^{27}$ Hirshfeld et $a l .{ }^{28}$ defined a weight function for each atom in a molecule as: ${ }^{29}$

$$
\mathrm{w}(\mathrm{r})=\sum_{\text {a } m \text { molecule }} \rho_{\mathrm{a}}(\mathrm{r}) / \sum_{\text {a } \mathrm{c} \text { crystal }} \rho_{\mathrm{a}}(\mathrm{r})=\rho_{\text {molecule }}(\mathrm{r}) / \rho_{\text {crystal }}(\mathrm{r})
$$

where $\mathrm{w}(\mathrm{r})$ is a continuous function with $0<\mathrm{w}(\mathrm{r})<1$, the term $\rho_{\mathrm{a}}(\mathrm{r})\left[\rho_{\text {molecule }}(\mathrm{r})\right]$ is a sum over the atoms in the molecule of interest and $\rho_{a}(r)\left[\rho_{\text {crystal }}(r)\right]$ is an analogous sum<smiles>COc1cc(C=CC(=O)c2ccc(NO)cc2N)cc(OC)c1OC</smiles>

Figure 1. Synthesis scheme for compound $\mathbf{I}$. 
over the crystal. ${ }^{26}$ In the Hirshfeld surface (HS), $d_{e}$ is the distance from the surface to the nearest nucleus in another molecule and the $\mathrm{d}_{\mathrm{i}}$ is the distance from the surface to the nearest atom in the molecule itself. The combination $d_{e}$ with $\mathrm{d}_{\mathrm{i}}$, gives rise to the normalized surface $\mathrm{d}_{\text {norm }}$, in which any close intermolecular contact will be characterized by two identical red regions. ${ }^{27,30}$

$d_{\text {norm }}=\frac{d_{i}-r_{i}^{\text {vdW }}}{r_{i}^{\text {vdW }}}+\frac{d_{e}-r_{e}^{\mathrm{vdW}}}{r_{e}^{v d W}}$

where $\mathrm{r}^{\mathrm{vdW}}$ is the van der Waals $(\mathrm{vdW})$ radius of atom internal or external to the surface. ${ }^{30} \mathrm{~A}$ final analysis of the intermolecular contacts can be conducted by twodimensional mapping which summarizes quantitatively the nature and type of intermolecular interaction and presents it in a graphical format, namely fingerprints. ${ }^{31}$

\section{Theoretical analysis}

Theoretical calculations were performed for both chalcones from the crystallographic data. Both geometries were optimized only for the hydrogen atoms $(\mathrm{opt}=$ readfreeze and atoms $=\mathrm{H}$ noatoms $=\mathrm{C}, \mathrm{O}, \mathrm{N})$, using the density functional theory (DFT) accomplished in the Gaussian09 package. ${ }^{32}$ We used $\mathrm{M} 062 \mathrm{X}^{33}$ as functional and $6-311 \mathrm{pG}(\mathrm{d}, \mathrm{p})^{34,35}$ as basis set. This functional is recommended for noncovalent interaction such as $\mathrm{C}-\mathrm{H} \cdots \mathrm{O}$ and $\mathrm{C}-\mathrm{H} \cdots \pi \cdot{ }^{36}$ The wavefunction generated using M062X / 6-311pG(d,p) was used for frontier molecular orbitals and molecular electrostatic potential map (MEP). The frontier molecular orbitals (highest occupied molecular orbital (HOMO) and the lowest unoccupied molecular orbital (LUMO)) is often associated with the electron donating ability of a molecule. ${ }^{37}$ The energy of these orbitals can be calculated and are associated with the chemical stability index and the difference between them (gap) is related to the chemical reactivity, being described as to the minimum energy needed to excite an electron in the molecule. ${ }^{38}$ The MEP presents the charge distribution of molecules three-dimensionally, and can determine regions of higher and lower electron densities of the molecule, contributing to interpret electrophilic and nucleophilic processes. ${ }^{39,40}$ For the two compounds shown, this mapping contributes to the comparison of the reactive sites in the presence of the benzodioxol group.

\section{Molecular docking}

In order to identify potential target candidates for the given chalcones, the pharmacophore mapping approachs were carried out. Binding properties for compounds I and II on potential target were estimated by PharmMapper Server. ${ }^{41}$ Just human protein target set was used for pharmacophore mapping, whatever remains of parameters was set to default. All the predicted target candidates were ranked by normalized fit score. Between the different targets predicted we had explored the molecule for its inhibitor activity against human beta-secretase 1 (BACE-1). BACE-1 represents a key target protein in the development of new potential drugs for the non-symptomatic treatment of Alzheimer's disease. Since BACE-1 was identified, a scope of work has been done in the drug discovery of new BACE-1 inhibitors. ${ }^{42}$ Molecular docking includes the expectation of the complex among protein and ligand into the protein active site, and empowers the most positive conformation to be resolved. Molecular docking was carried out to evaluate the binding affinity of the compounds with the BACE-1 active site. The protein $\mathrm{X}$-ray crystal structure was downloaded from the Protein Data Bank (PDB). ${ }^{43}$

The active site of protein was predicted using CASTp. ${ }^{44}$ The best binding pocket was selected for further analysis. The 3D structures of BACE-1 and ligand were prepared as input for docking experiments using Dock Prep tool of Chimera software. ${ }^{45}$ During the protein preparation, all missing hydrogen atoms were added, all water molecules and ligand deleted, and the energy minimized. Protein and ligand were dealt with the general AMBER force field 12SB ${ }^{46}$ All other settings were kept as default setting. The molecular docking calculations were performed on AutoDock Vina software. ${ }^{47}$ First, the active site of the enzyme was defined within two different grid size $12.45 \times 12.69 \times 13.70 \AA$ and $20 \times 20 \times 20 \AA$ centred at the geometric point $(70.32,47.34,5.34 \AA)$ on co-crystallized ligand. For each docking calculation nine docking runs were carried out with an exhaustiveness option of eight, and the poses with the highest absolute values of affinity were saved with maximum energy difference of $3 \mathrm{kcal} \mathrm{mol}^{-1}$.

\section{Results and Discussion}

\section{Solid state characterization}

The molecular structure of compound I was crystallized under monoclinic $\mathrm{P} 2_{1} / \mathrm{c}$ space group with unit cell parameters $a=12.7264$ (3) $\AA, b=8.6478$ (2) $\AA, c=15.2955$ (4) $\AA$ and $\beta=103.8320(10)^{\circ}$. Compound II was crystallized under $\mathrm{P} 2_{1} / \mathrm{c}$ monoclinic space group with cell parameters, $a=23.5477$ (4) $\AA, b=4.9605$ (1) $\AA, c=14.2556$ (8) $\AA$ and $\beta=100.702(1)^{\circ}$. ORTEP representation of compounds I and $\mathbf{I I}$ are presented in Figure 2. 

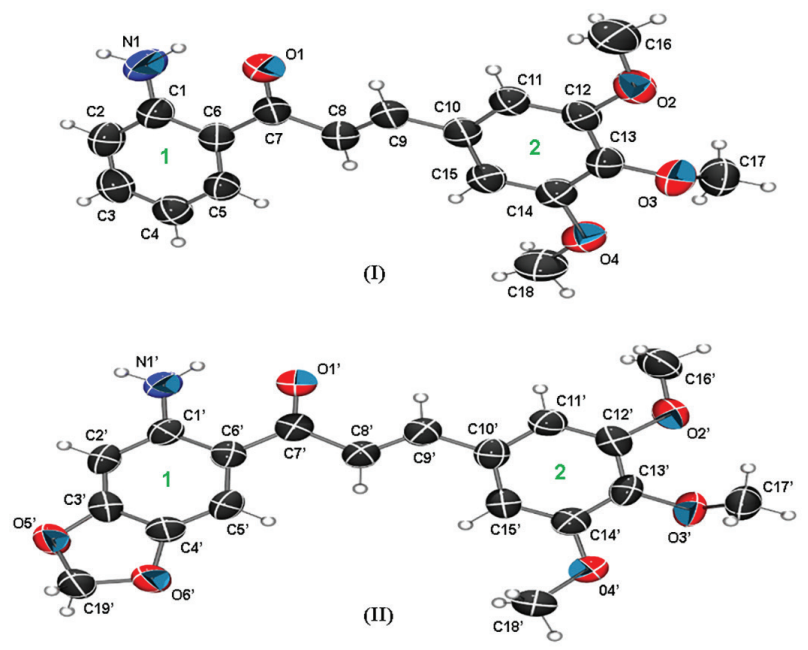

Figure 2. ORTEP representation at $50 \%$ of probability for compounds I and II. Hydrogen atoms are shown as spheres of arbitrary radii.

Both compounds I and II have a trimethoxy group at one of the extremities, attached to $\mathrm{C} 12, \mathrm{C} 13$ and $\mathrm{C} 14$ atoms from ring 2 in compound $\mathbf{I}$ and $\mathbf{C} 12^{\prime}, \mathrm{C} 13$ ' and C14' from ring 2 in compound II. On the other hand, they differ in the aromatic ring 1, since compound $\mathbf{I}$ has an amino group attached to the aromatic ring, while compound II has a benzodioxol group attached to the aromatic ring, according to ORTEP representations in Figure 2. Besides that, although methoxy groups have similar angles $\left(\mathrm{C} 13-\mathrm{O} 3-\mathrm{C} 17=113.74^{\circ}\right.$ for $\mathbf{I}$ and $\mathrm{C} 13^{\prime}-\mathrm{O} 3^{\prime}-\mathrm{C}^{\prime} 7^{\prime}=114.08^{\circ}$ for II), they are oriented in opposite directions (Figure 3).

The observed planarity in I and II is confirmed from dihedral angles $\omega 1, \omega 2, \omega 3, \omega 4, \omega 5, \omega 6, \omega 7$ and $\omega 8$ (Table 2). Structural differences between $\mathbf{I}$ and II are evidenced from dihedral angles $\omega 2$ and $\omega 6\left(-4.77^{\circ} ; 1.03^{\circ}\right)$, $\omega 3$ and $\omega 7\left(7.71^{\circ} ; 9.40^{\circ}\right), \omega 4$ and $\omega 8\left(9.05^{\circ} ; 12.18^{\circ}\right)$.

The Figure 3 shows on overlap, relating the angles formed by planes of aromatic ring of $\mathbf{I}$ and the benzodioxol
Table 2. Dihedral angles for I and II

\begin{tabular}{lcc}
\hline Atoms & Dihedral angles / degree & \\
\hline C8-C9-C10-C15 & 5.65 & $\omega 1$ \\
C9-C8-C7-O1 & -4.77 & $\omega 2$ \\
C1-C6-C7-O1 & 7.71 & $\omega 3$ \\
C5-C6-C7-C8 & 9.05 & $\omega 4$ \\
C8'-C9'-C10'-C15' & 4.35 & $\omega 5$ \\
C9'-C8'-C7'-O1' & 1.03 & $\omega 6$ \\
C1'-C6'-C7'-O1' & 9.40 & $\omega 7$ \\
C5'-C6'-C7'-C8' & 12.18 & $\omega 8$ \\
\hline
\end{tabular}

ring of II ( $\delta_{1}=12.47$ and $\delta_{2}=18.58^{\circ}$ respectively). The difference between planes angles $\left(\delta_{1}\right.$ and $\left.\delta_{2}\right)$ is $6.11^{\circ}$, showing that the presence of the benzodioxol group increases the distance from the plane when compared to the aromatic ring of $\mathbf{I}$.

The crystal packing of $\mathbf{I}$ is stabilized by $\mathrm{C}-\mathrm{H} \cdots \mathrm{O}$, $\mathrm{N}-\mathrm{H} \cdots \pi$ and $\mathrm{C}-\mathrm{H} \cdots \pi$ interactions (Figure $4 \mathrm{a}$ ), while $\mathbf{I I}$ by $\mathrm{C}-\mathrm{H} \cdots \mathrm{O}, \mathrm{N}-\mathrm{H} \cdots \mathrm{O}$ and $\mathrm{C}-\mathrm{H} \cdots \pi$ interactions (Figure $4 \mathrm{~b}$ ). Both structures have an intramolecular interaction involving amine and carbonyl groups. The interactions $\mathrm{C} 3-\mathrm{H} 3 \cdots \mathrm{O} 1$ and $\mathrm{C} 5-\mathrm{H} 5 \cdots \mathrm{O} 2$ form chains running along [001] and [010], respectively. In contrast, interactions $\mathrm{C} 11^{\prime}-\mathrm{H} 11^{\prime} \ldots \mathrm{O}{ }^{\prime}$ ' and C9'-H9'... O6' (bifurcate) contribute to the periodicity along [001], while interactions $\mathrm{C}^{19} 9^{\prime}-\mathrm{H} 19 \mathrm{~A}^{\prime} \cdots \mathrm{Cg} 11^{\prime}$, C18'-H18A' $\cdots \mathrm{Cg} 2$ ' and $\mathrm{C} 16^{\prime}-\mathrm{H} 16 \mathrm{~A}^{\prime} \cdot{ }^{\prime} \cdot \mathrm{Cg} 2$ ' are observed along [010]. Compound II form a dimer stabilized by interaction $\mathrm{N} 1$ ' $-\mathrm{H} 1 \mathrm{~B}$ '... O5' which contributes for the crystalline packing, occuring due to the presence of the benzodioxol group. For both $\mathbf{I}$ and II, intramolecular interactions $\mathrm{N} 1-\mathrm{H} 1 \mathrm{~A} \cdots \mathrm{O} 1$ and $\mathrm{N} 1$ '- $-\mathrm{H} 1 \mathrm{~A}^{\prime} \cdots \mathrm{O} 1$ ' collaborate for the structure's planarity, but with benzodioxol group it is observed a smaller planarity, increasing the $\delta$ value from 12.47 (I) to $18.58^{\circ}$ (II). This planarity deviation is result of

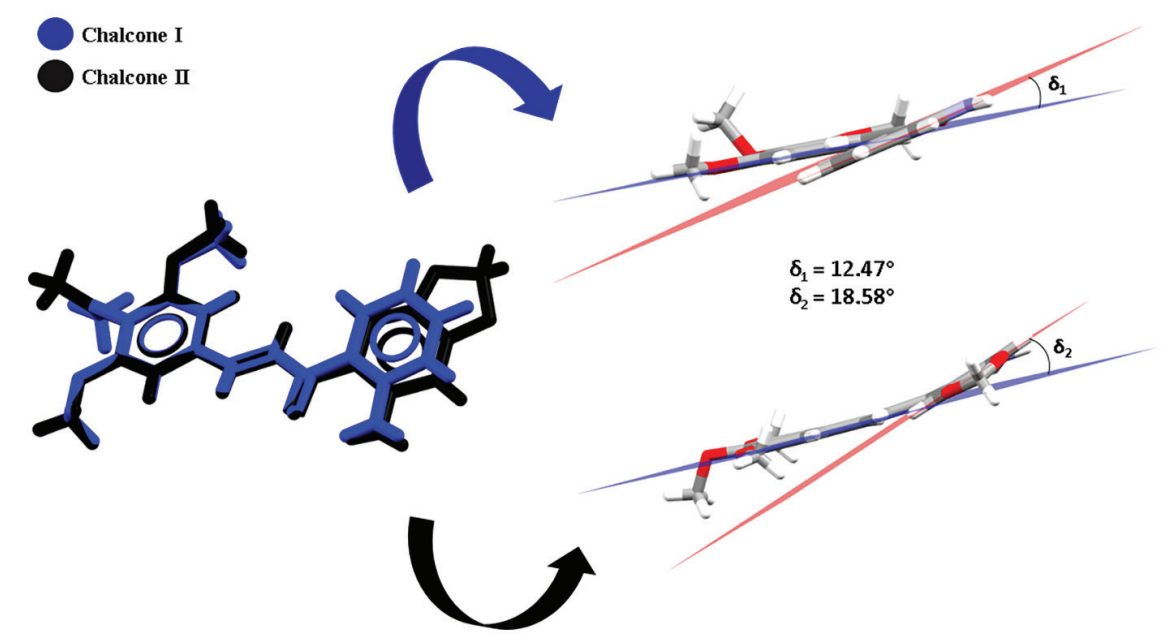

Figure 3. Overlapping for compounds I and II. 
the benzodioxol group electronegativity, which causes more intermolecular interactions. The total information about the interactions of $\mathbf{I}$ and II are shown in Table 3.

HS was used to improve the intermolecular interactions description. ${ }^{27}$ Figure 5 shows the Hirshfeld surface $d_{\text {norm }}$ for both analyzed compounds. This surface normalizes $d_{e}$ and $d_{i}$ as a function of the van der Waals radius, indicating on its surface both donor and acceptor regions of intermolecular contacts. In this sense, molecular interactions are recognized from a color-based scale, where red indicates strong contacts. In Figures $5 \mathrm{a}$ and $5 \mathrm{~b}$, are indicated the intermolecular interactions of $\mathbf{I}$, while $5 \mathrm{c}$ indicates

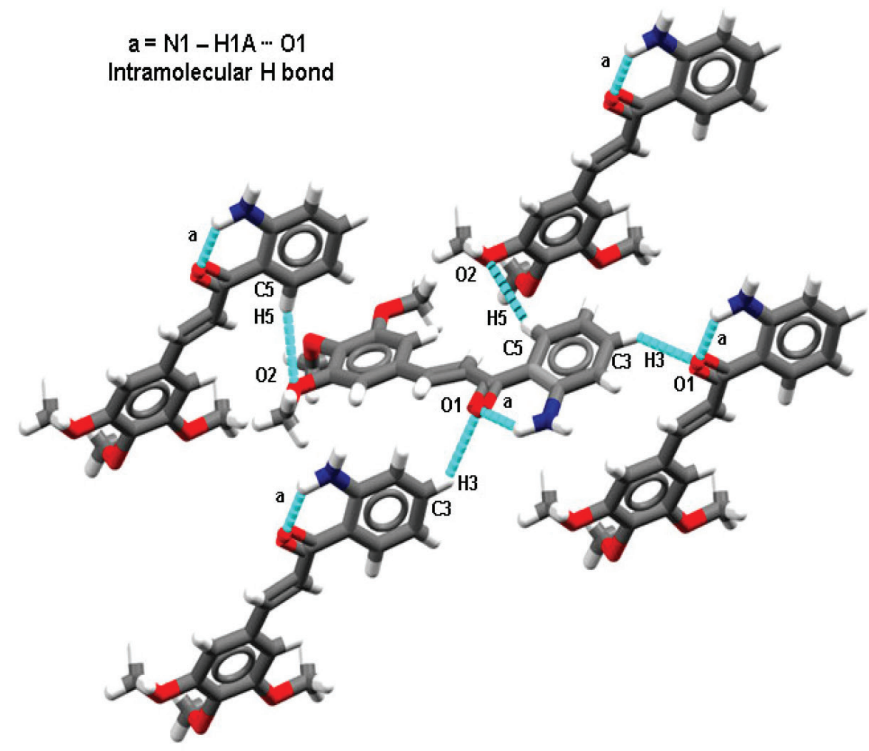

(a) interactions of II. For I, the regions (1r), (3r) and (5r) indicate acceptor regions of interactions $\mathrm{N} 1-\mathrm{H} 1 \mathrm{~B} \cdots \mathrm{Cg} 1$,

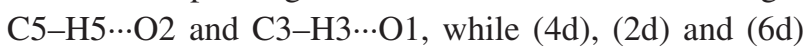
represent their donor regions. For II, (2r'), (4r') and (6r') indicate acceptor regions of interactions $\mathrm{N1}$ '-H1B' ...O5', C1'-H11'...O6' and C9'-H9'...O6', while (1d'), (3d') and (5d') describe their donor regions, respectively. For I, the more intense color of (1r) and (4d) indicates that the interaction $\mathrm{N} 1-\mathrm{H} 1 \mathrm{~B} \cdots \mathrm{Cg} 1$ plays an important role on its crystals packing, while the crystal packing II is stabilized mainly by the interaction $\mathrm{C} 1$ '-H11'... O6', as seen in (4r') and (6d') contacts.

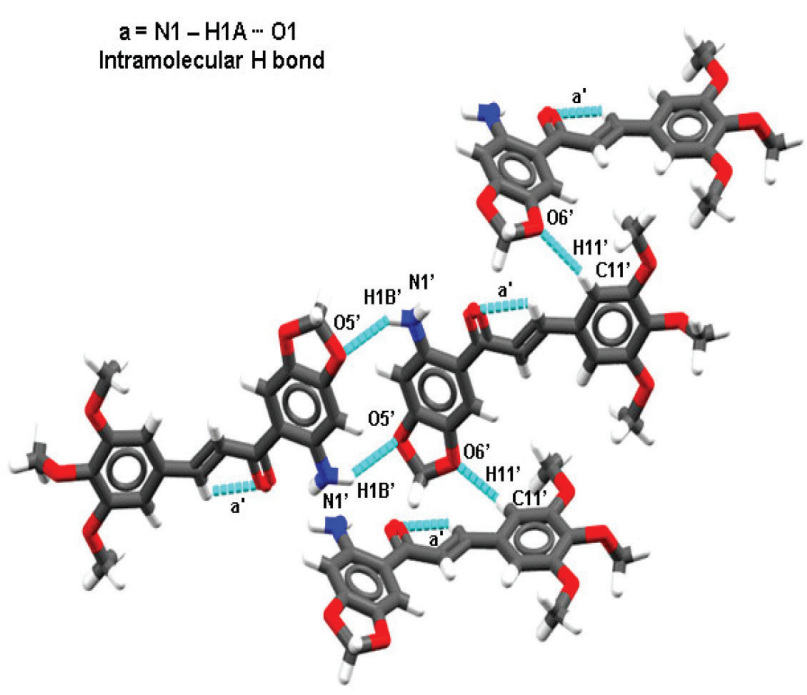

(b)

Figure 4. Representation of interactions for compounds (a) I and (b) II.

Table 3. Total interactions for compounds I and II

\begin{tabular}{|c|c|c|c|c|c|}
\hline Compound & D-H $\cdots A$ & $\mathrm{~d}(\mathrm{D}-\mathrm{H}) / \AA$ & $\mathrm{d}(\mathrm{H} \cdots \mathrm{A}) / \AA$ & $\mathrm{d}(\mathrm{D} \cdots \mathrm{A}) / \AA$ & $\mathrm{d}(\mathrm{D}-\mathrm{H} \cdots \mathrm{A}) /$ degree \\
\hline \multirow{6}{*}{ I } & $\mathrm{C} 3-\mathrm{H} 3 \cdots \mathrm{O} 1^{\mathrm{a}}$ & 0.930 & 2.619 & 3.344 & 135.25 \\
\hline & $\mathrm{C} 5-\mathrm{H} 5 \cdots \mathrm{O} 2^{\mathrm{b}}$ & 0.930 & 2.690 & 3.539 & 153.20 \\
\hline & $\mathrm{C} 9-\mathrm{H} 9 \cdots \mathrm{Cg} 1^{\mathrm{c}}$ & 0.930 & 2.879 & 3.647 & 140.82 \\
\hline & $\mathrm{N} 1-\mathrm{H} 1 \mathrm{~B} \cdots \mathrm{Cg} 1^{\mathrm{d}}$ & 0.866 & 3.197 & 4.005 & 156.22 \\
\hline & $\mathrm{C} 4-\mathrm{H} 4 \cdots \mathrm{Cg} 2^{\mathrm{b}}$ & 0.930 & 3.496 & 3.954 & 113.09 \\
\hline & N1-H1A …O1 (intra) & 1.017 & 1.844 & 2.621 & 130.40 \\
\hline \multirow{7}{*}{ II } & C19'-H19A'‥Cg1'e & 0.990 & 2.923 & 3.564 & 123.30 \\
\hline & $\mathrm{C} 11^{\prime}-\mathrm{H} 11^{\prime} \cdots 6^{\prime b}$ & 0.951 & 2.510 & 3.398 & 155.43 \\
\hline & $\mathrm{C} 9^{\prime}-\mathrm{H} 9^{\prime} \cdots \mathrm{O}^{\prime}{ }^{\mathrm{b}}$ & 0.950 & 2.694 & 3.546 & 149.53 \\
\hline & $\mathrm{C} 18^{\prime}-\mathrm{H} 18 \mathrm{~A}^{\prime} \cdots \mathrm{Cg} 2^{\prime}{ }^{\prime}$ & 0.981 & 2.814 & 3.675 & 146.93 \\
\hline & $\mathrm{C} 16^{\prime}-\mathrm{H} 16 \mathrm{~A}^{\prime} \cdots \mathrm{Cg} 2^{\prime}{ }^{\prime}$ & 0.980 & 2.754 & 3.626 & 148.60 \\
\hline & $\mathrm{N} 1^{\prime}-\mathrm{H} 1 \mathrm{~B}^{\prime} \cdots \mathrm{O} 5^{\prime}{ }^{\mathrm{f}}$ & 0.880 & 2.645 & 3.357 & 138.69 \\
\hline & N1'-H1A'‥O1' (intra) & 0.880 & 2.007 & 2.651 & 129.09 \\
\hline
\end{tabular}

${ }^{\mathrm{a} x}, 3 / 2-\mathrm{y}, 1 / 2+z ;{ }^{\mathrm{b} x}, 1 / 2-\mathrm{y}, 1 / 2+\mathrm{z} ;{ }^{\mathrm{c}} \mathrm{x}, 3 / 2-\mathrm{y},-1 / 2+\mathrm{z} ;{ }^{\mathrm{d}}-\mathrm{x}, 1 / 2+\mathrm{y}, 3 / 2-\mathrm{z} ;{ }^{\mathrm{e}} \mathrm{x},-1+\mathrm{y}, \mathrm{z} ;{ }^{\mathrm{f}}-\mathrm{x}, 1-\mathrm{y},-\mathrm{z}$ 
In addition, the shape index assists in the interpretation of interactions occurring between delocalized $\pi$ systems $(\pi \pi, \mathrm{C}-\mathrm{H} \cdots \pi$ or $\mathrm{N}-\mathrm{H} \cdots \pi$ interactions). Figure 6 shows that both $\mathbf{I}$ and $\mathbf{~ I I}$ are stabilized by $\mathrm{C}-\mathrm{H} \cdots \pi$ interactions, represented by a concave red region over the aromatic ring (Figure $6 \mathrm{~b}$ for $\mathbf{I}$ and Figure $6 \mathrm{~d}$ for $\mathbf{I I}$ ). Figures $6 \mathrm{a}$ and $6 \mathrm{~b}$ show that I is stabilized by N1-H1B $\cdots \mathrm{Cg} 1(i), \mathrm{C} 9-\mathrm{H} 9 \cdots \mathrm{Cg} 1$ (ii) and $\mathrm{C} 4-\mathrm{H} 4 \cdots \mathrm{Cg} 2$ (iii) interactions. Figures $6 \mathrm{c}$ and $6 \mathrm{~d}$ show that $\mathbf{I I}$ is stabilized by three $\mathrm{C}-\mathrm{H}^{\cdots} \cdots \pi$ interactions, C19'-H19B' '...Cg1' (i'), C18'-H18C'...Cg2' (ii') and

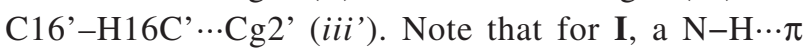
interaction is present involving the ring $1(\mathrm{Cg} 1)$, while for II, a $\mathrm{C}-\mathrm{H} \cdots \pi$ interaction occurs in the ring $1(\mathrm{Cg} 1$ '), due to the presence of the benzodioxol group.

A plot of the $d_{e} v s . d_{i}$ distribution, called the fingerprint, was constructed and represents the percentage of all interactions present in the molecules (Figure 7). Both I and II are organic molecules, so the hydrogen interactions represented by $\mathrm{H} \cdots \mathrm{H}$ in Figure 7, represent almost 50\% of the total interactions. In addition, $\mathrm{C} \cdots \mathrm{H}$ contacts corresponds to $\mathrm{C}-\mathrm{H} \cdots \pi$ or $\mathrm{N}-\mathrm{H} \cdots \pi$ interactions, while $\mathrm{O} \cdots \mathrm{H}$ contacts indicate the $\mathrm{C} 3-\mathrm{H} 3 \cdots \mathrm{O} 1$ and $\mathrm{C} 5-\mathrm{H} 5 \cdots \mathrm{O} 2$ interactions for I and C11'-H1 1'... O6', C9'-H9' ...O6' and N1'-H1B'...O5' for II.

Theoretical analysis

The MEP map helps to interpret the chemical properties for a system ${ }^{39}$ and Figure 8 shows this map for compounds I and II. The red color regions indicate electrophilic sites, being located over oxygen atoms for both I and II. On the other hand, blue color sites indicate nucleophile sites and are concentrated in both chalcones over hydrogen atoms and amine groups. Note that in $\mathbf{I}$ the electrophilic and nucleophile sites, are slightly more pronounced than the corresponding region in II, caused by benzodioxol group.

The HOMO and LUMO energies were calculated for both chalcones using M062X/6-311++G (d, p) theory level, and their graphical surfaces are shown in Figure 9. The difference (gap) between HOMO and LUMO energies is an important indicator for molecular chemical reactivity. ${ }^{48,49}$ For $\mathbf{I}$, the energies of HOMO, LUMO and gap are $-7.022034 \mathrm{eV}$, $-1.365441 \mathrm{eV}$ and $545.778375 \mathrm{~kJ} \mathrm{~mol}^{-1}$, respectively. The HOMO orbital is spread over nitrobenzene ring, while the LUMO orbital is over carbonyl and olefin portions. For II these values are $-6.760622 \mathrm{eV},-1.342188 \mathrm{eV}$, $522.799589 \mathrm{~kJ} \mathrm{~mol}^{-1}$, respectively. Similar to I, the LUMO orbital is spread over ring 1 and HOMO orbital is observed close to open chain. In this sense, the benzodioxol group has not influence on the frontier molecular orbitals location. On the other hand, this group slightly decreases the reactivity of II when compared to I, as evidenced from gap energies.

Molecular modeling analysis

Compounds I and II were screened in silico with

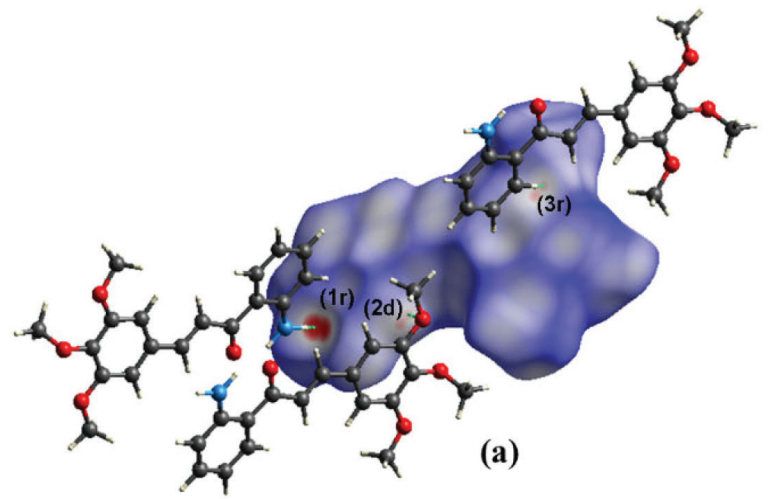

(a)

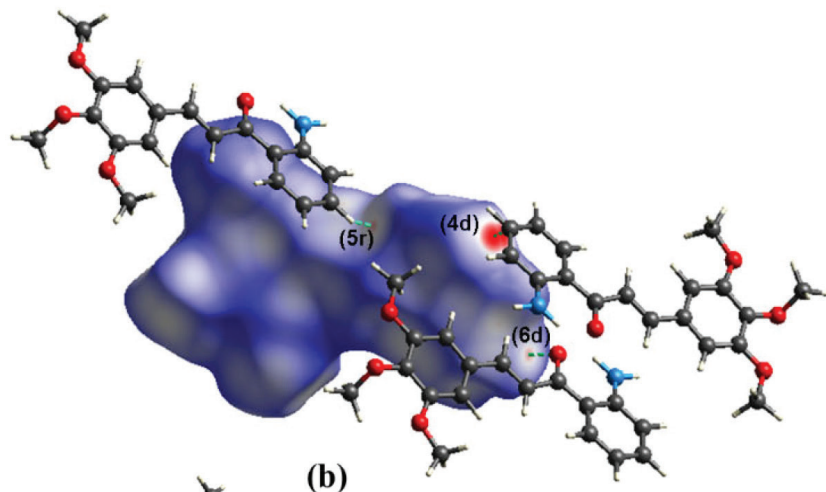

(b)
$(1 \mathrm{r})$ and $(4 \mathrm{~d})=\mathrm{N} 1-\mathrm{H} 1 \mathrm{~B} \cdots \mathrm{Cg} 1$ (2d) and $(3 \mathrm{r})=\mathrm{C} 5-\mathrm{H} 5 \cdots \mathrm{O} 2$ $(5 \mathrm{r})$ and $(6 \mathrm{~d})=\mathrm{C} 3-\mathrm{H} 3 \mathrm{O} 1$

$\left(1 d^{\prime}\right)$ and $\left(2 r^{\prime}\right)=\mathrm{N}^{2}-\mathrm{H}^{\prime} \mathrm{B}^{\prime} \cdots \mathrm{O}^{\prime}$ $\left(3 d^{\prime}\right)$ and $\left(4 r^{\prime}\right)=\mathrm{C}^{\prime}-\mathrm{H}^{\prime} 1^{\prime}-\mathrm{O}^{\prime}$ $\left(5 d^{\prime}\right)$ and $\left(6 r^{\prime}\right)=\mathrm{C}^{\prime}-\mathrm{H}^{\prime} \cdots \mathrm{O}^{\prime}$

(c)

Figure 5. Hirshfeld surface ( $\mathrm{d}_{\text {norm }}$ ) evidencing interactions for compound I, (a) and (b), and for compound II, (c). 
(I)

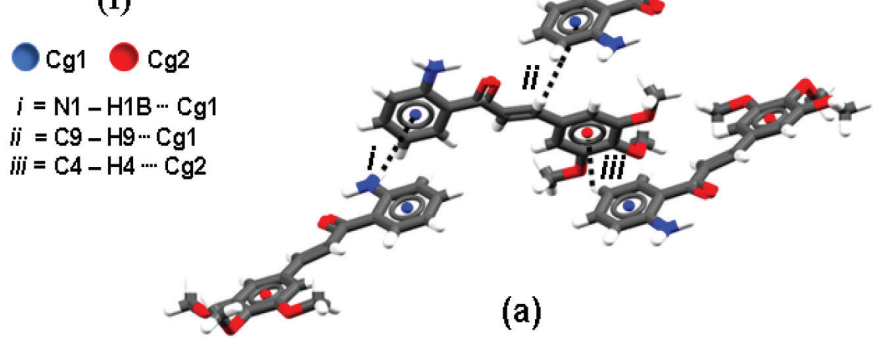

(II)

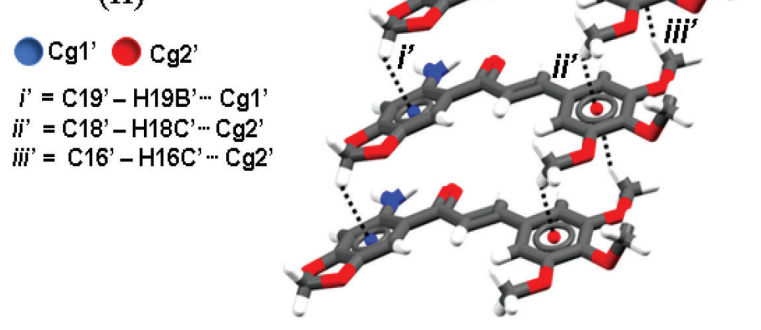

(c)
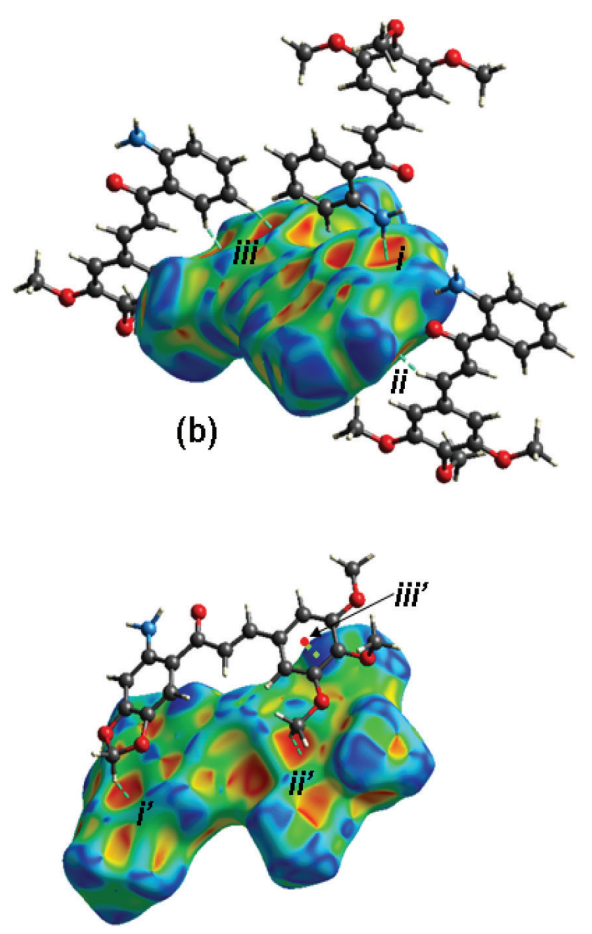

(d)

Figure 6. Hirsfeld surface shape index and representation of the interactions $\mathrm{C}-\mathrm{H} \cdots \pi$ and $\mathrm{N}-\mathrm{H} \cdots \pi$ for compound $\mathbf{I}$, (a) and (b). C-H $\cdots \pi$ interactions for compound II, (c) and (d).

(I)

\begin{tabular}{|c|c|c|}
\hline $17.30 \%$ & $50.10 \%$ & $28.40 \%$ \\
\hline $26.20 \%$ & $40.90 \%$ & $23.4 \%$ \\
\hline
\end{tabular}

๑... H

H.... H

$\square \mathrm{C} \ldots \mathrm{H}$

Others

(a)

(I)

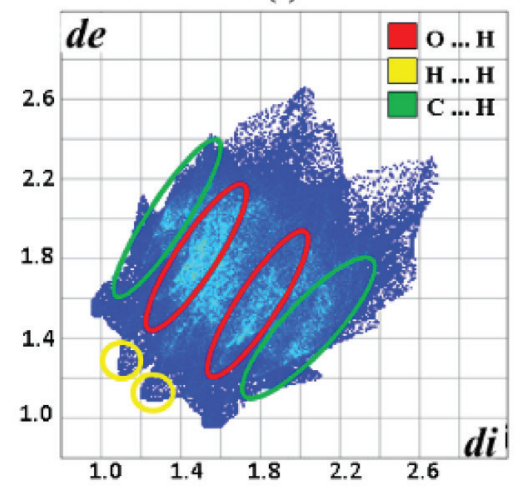

(b)
(II)

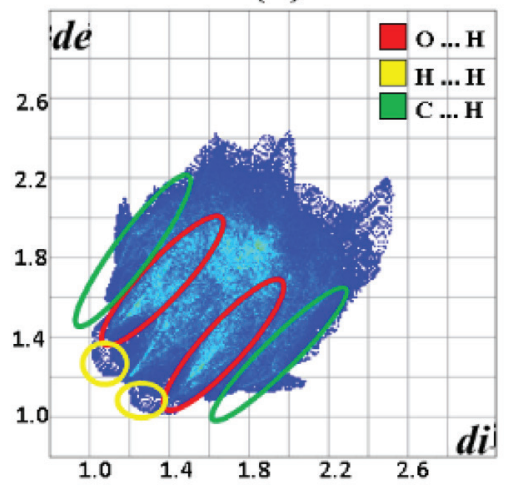

(c)

Figure 7. Quantitative analysis of the contacts for compounds I and II (a), and their fingerprints (b) and (c).

PharmMapper to elucidate their potential protein targets. The PharmMapper server revealed for both compounds I and II the human protein beta-secretase 1 (PDB code: $2 \mathrm{OHQ})^{50}$ with 3 hydrophobic and 1 hydrogen bond donor features and the values 0.73 and 0.68 normalized fit score, respectively. Besides that, previous work ${ }^{18}$ has shown that chalcone derivatives are very potent inhibitors of protein beta-secretase 1, such as compound II ((half maximal 

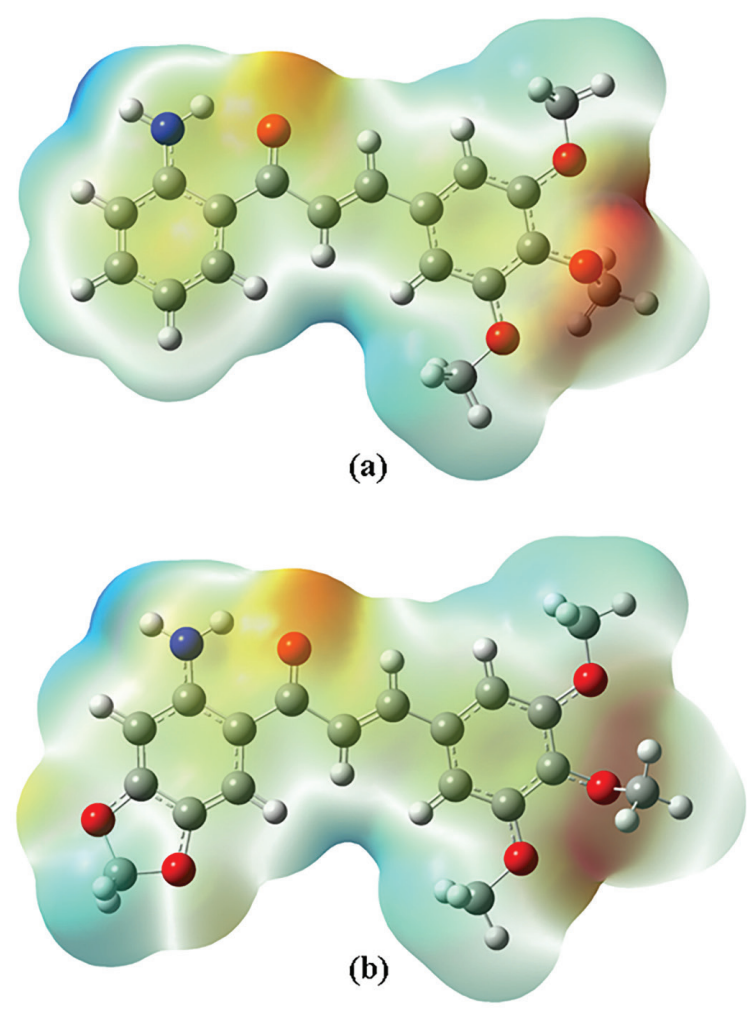

Figure 8. Molecular electrostatic potential (MEP) surface calculated at M062X/6-311 pG (d,p) for compounds I (a) and II (b). The density range for $\mathbf{I}$ is $-5.367 \mathrm{e}-2$ to $5.367 \mathrm{e}-2$ hartrees, and for $\mathbf{I I}$ is $-5.902 \mathrm{e}-2$ to $5.902 \mathrm{e}-2$. inhibitory concentration $\left.\left(\mathrm{IC}_{50}\right)=17.7 \mu \mathrm{M}\right)$ which has maximum common substructure Tanimoto score of 0.75 and 0.66 with the compounds I and II described in the present work.

Initially, the ligand binding process was validated by redocking of the co-crystallized 6-[2-(3'-methoxybiphenyl3-yl) ethyl]pyridin-2-amine (7IP) inside of 2OHQ structure to reproduce its binding mode. In this case, root mean square deviation (RMSD) values less than $2 \AA$ between the redocking ligand pose and the co-crystallized ligands are satisfactory. ${ }^{51,52}$ The both redocking protocol reproduced the binding mode of the co-crystallized ligand with RMSD values equal to 0.49 and $1.34 \AA$ for the two different grid size, respectively. The AutoDock Vina score in redocking result for 2OHQ is -7.4 and $-7.6 \mathrm{kcal} \mathrm{mol}^{-1}$, in its turn the experimental affinity of the complex 2OHQ-7IP shows a similar value of $\Delta \mathrm{G}_{\text {exp }}=-8.9 \mathrm{kcal} \mathrm{mol}^{-1}\left(\mathrm{IC}_{50} 25 \mu \mathrm{mol} \mathrm{L}^{-1}\right){ }^{45}$ These is sufficient to define a docking protocol. Figure 10 shows how this ligand makes good contact with the active site and forms an H-bonding interaction with the catalytic aspartic acid residue Asp32.

The validated protocol was set up and the compounds I and II were docked inside the BACE-1 active site using the smaller grid size. After docking running the compounds were ranked and the best pose for a given ligand was

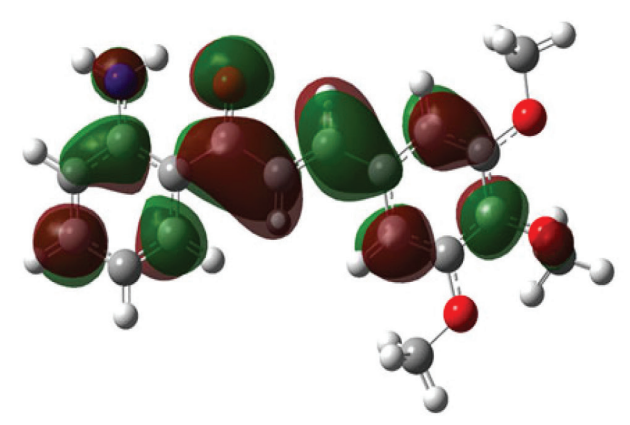

$\mathrm{E}_{\text {LUMO }}=-131.74498 \mathrm{~kJ} \mathrm{~mol}^{-1}$

Gap $=545.77807 \mathrm{~kJ} \mathrm{~mol}^{-1}$

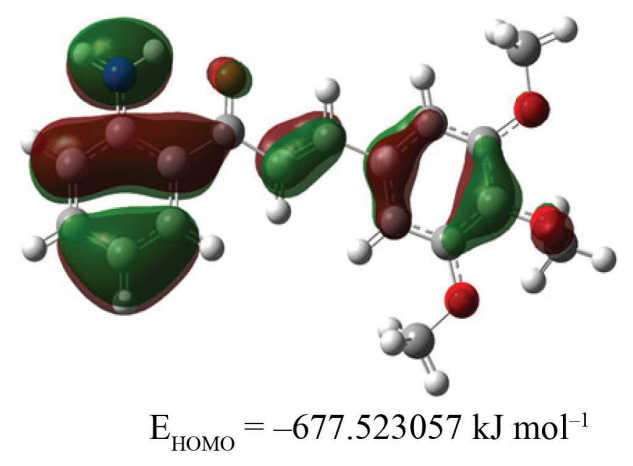

(a)

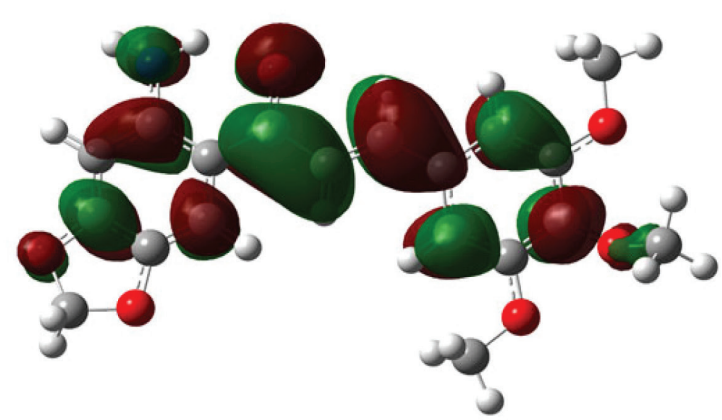

$\mathrm{E}_{\mathrm{LUMO}}=-129.501412 \mathrm{~kJ} \mathrm{~mol}^{-1}$

Gap $=522.79923 \mathrm{~kJ} \mathrm{~mol}^{-1}$

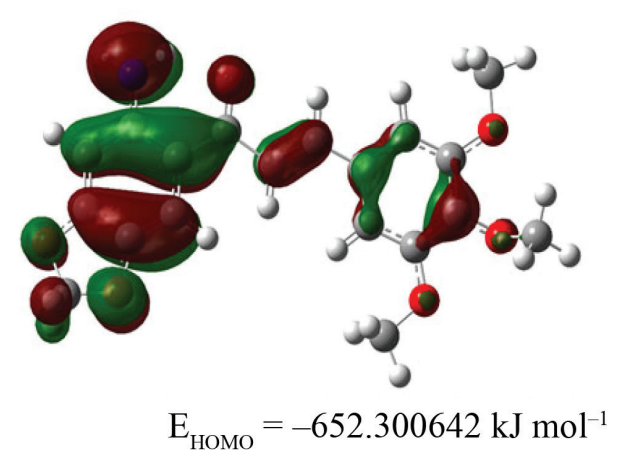

(b)

Figure 9. Frontier molecular orbitals of compounds (a) I and (b) II, with HOMO and LUMO band-gaps distribution. 

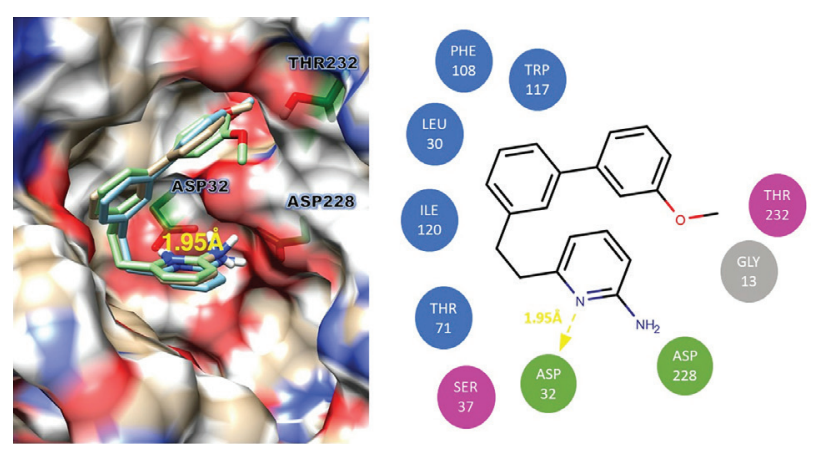

Figure 10. Redocking results of co-crystallized ligand 7IP (0.49 ̊ $\tan )(1.34 \AA$ - green) inside BACE-1 active site (PDB, code 2OHQ). Superposition between co-crystallized in sky blue and the best docking pose predicted in tan and green with the protein surface represented by heteroatom. The residues Asp32, Asp228 and Thr232 are represented in stick. The two-dimensional representation is showed on the right-hand side with the key residues. Yellow dashed lines represent hydrogen bond, blue circles are hydrophobic interactions and purple circles, the polar interactions. Molecular graphic was performed with the UCSF Chimera package. $^{45}$

determined by the AutoDock Vina score. ${ }^{47}$ Figure 11a presents the docking results for $\mathbf{I}$ and $\mathbf{I I}$ inside the active site of 2OHQ structure. The active site predicted by CASTp is represented by heteroatom surface. It was observed that both compounds bound to the BACE-1 active site with AutoDock Vina score of $-6.0 \mathrm{kcal} \mathrm{mol}^{-1}$.

From interactions formed between both compounds and BACE-1, it was verified that some residues in the binding pocket interact with the chalcones derived compounds through hydrogen bonding and hydrophobic interactions as predicted by PharmMapper. From CASTp results, the BACE-1 pocket shows a hydrophobic sub pocket (represented by green residues on Figures $11 \mathrm{~b}$ and 11c) suggesting that hydrophobic groups should be tolerated in this region. Figures $11 \mathrm{~b}$ and $11 \mathrm{c}$ show how the 3,4,5-trimethoxyphenyl group makes good contact with the hydrophobic sub pocket. In addition, the compounds interact with the flap residue, Tyr71, on hydrophobic sub pocket, the flap conformation is identical to the flap-closed conformation described by Patel et al..${ }^{53}$ and Hong and Tang. ${ }^{54}$ The hydrogen bond was observed between the amine group of $\mathbf{I}$ and $\mathbf{I I}$, and the catalytic aspartic acid residue (Asp32). BACE-1 is a hydrolytic enzyme, its enzymatic activity is driven by Asp dyad (Asp32 and Asp228) located at active site where the peptides are hydrolysed. The visual inspection helped to identify more "good contacts" between the enzyme and the group benzyl in I than the group benzodioxol of II. The results analysed by docking studies propose them as potential candidates to BACE-1 inhibitors. Additionally, this binding mode can end up being a decent beginning stage for upgrading further chemical synthesis of chalcones derived compounds to inhibit beta-secretase 1 receptor using trimethoxy chalcones as scaffold.

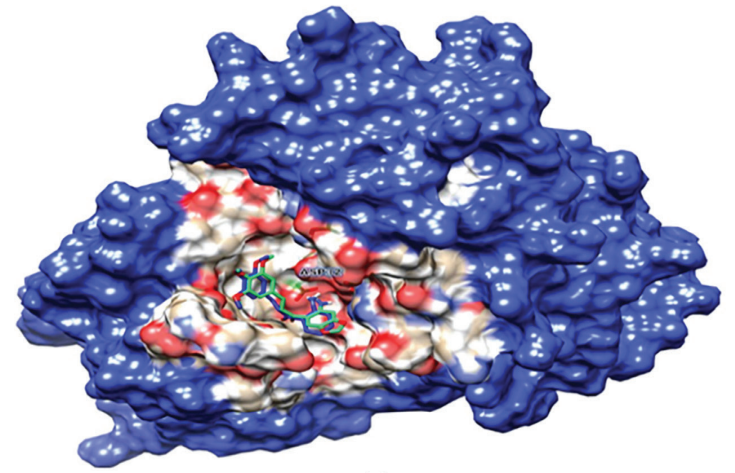

(a)
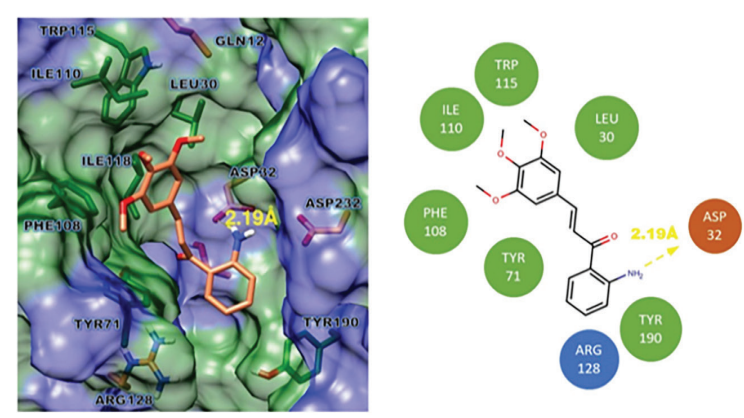

(b)
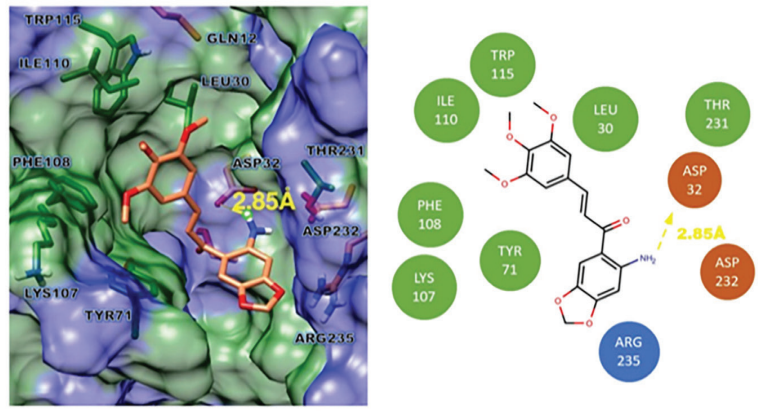

(c)

Figure 11. Docking results for compounds I and II in the 2OHQ BACE-1 crystallography structure. (a) The active site predicted by CASTp is represented by heteroatom surface, and the blue surface corresponds to the others residues of protein on the left-hand side. (b) and (c) On the middle, the compounds I and II making hydrogen bond (yellow dashed line) with catalytic aspartic acid residue (brown circle) and interacting with hydrophobic residues (green sticks and blue circles). The two-dimensional representation is appeared on the right-hand side.

\section{Conclusions}

The supramolecular arrangement of compound II has more interactions than I due to the presence of benzodioxole group, which makes II less planar than I, as observed throughout the angle between planes of aromatic rings. Except for the $\mathrm{N}-\mathrm{H} \cdots \pi$ interaction for $\mathbf{I}$, the crystalline state of both chalcones is stabilized by $\mathrm{C}-\mathrm{H} \cdots \mathrm{O}$ and $\mathrm{C}-\mathrm{H} \cdots \pi$ interactions, which were confirmed by the Hirshfeld surfaces. Geometry optimization was carried out using DFT, and MEP maps confirm benzodioxole regions 
more susceptible to interactions. The HOMO-LUMO gap for compound $\mathbf{I}$ is greater than for $\mathbf{I I}$, indicating high kinetic stability and low chemical reactivity in relation to compound II. Molecular docking simulations were used to explore the interactions between BACE- 1 and these two chalcones. The binding modes have suggested to be a good starting point for optimizing further chemical synthesis of chalcones derived compounds to inhibit beta-secretase 1 receptor, using tri-methoxy chalcones as scaffold.

\section{Supplementary Information}

Crystallographic data (excluding structure factors) for the structures in this work were deposited in the Cambridge Crystallographic Data Centre as supplementary publication number CCDC 1866290 and 180169. Copies of the data can be obtained, free of charge, via www.ccdc.cam.ac.uk/conts/ retrieving.html or from the Cambridge Crystallographic Data Centre, CCDC, 12 Union Road, Cambridge CB2 1EZ, UK; fax: +44 1223 336033. E-mail: deposit@ccdc.cam.ac.uk.

\section{Acknowledgments}

The authors are grateful to Programa de Apoio à Pós-graduação (PROAP, agreement 817164/2015) of the Coordenação de Aperfeiçoamento de Pessoal de Nível Superior (CAPES) and to Conselho Nacional de Desenvolvimento Científico e Tecnológico (CNPq) for the financial support. Also, the authors thank to the First Latin American Crystallography Association (LACA) School on Small Molecule Crystallography for the X-ray data collection of $\mathbf{I}$. Theoretical calculations were performed in the High Performance Computing Center of Universidade Estadual de Goiás (UEG).

\section{References}

1. Zhuang, C.; Zhang, W.; Sheng, C.; Zhang, W.; Xing, C.; Miao, Z.; Chem. Rev. 2017, 117, 7762.

2. Bukhari, S. N. A.; Jasamai, M.; Jantan, I.; Ahmad, W.; Mini-Rev. Org. Chem. 2013, 10, 73.

3. Liu, Y.; Zhang, X.; Kelsang, N.; Tu, G.; Kong, D.; Lu, J.; Zhang, Y.; Liang, H.; Tu, P.; Zhang, Q.; J. Nat. Prod. 2018, 81, 307.

4. Patil, C. B.; Mahajan, S. K.; Katti, S. A.; J. Pharm. Sci. Res. 2009, 11 .

5. Devia, A. C.; Ferretti, F. H.; Ponce, C. A.; Tomas, F.; J. Mol. Struct. 1999, 493, 187.

6. Nowakowska, Z.; J. Med. Chem. 2007, 42, 125.

7. Singh, P.; Anand, A.; Kumar, V.; Eur. J. Med. Chem. 2014, 85, 758.
8. Mahapatra, D. K.; Bharti, S. K.; Asati, V.; Eur. J. Med. Chem. 2015, 98, 69.

9. Silva, W. A.; Andrade, C. K. Z.; Napolitano, H. B.; Vencato, I.; Lariucci, C.; de Castro, M. R. C.; Camargo, A. J.; J. Braz. Chem. Soc. 2013, 24, 133.

10. Custodio, J. M. F.; Michelini, L. J.; de Castro, M. R. C.; Vaz, W. F.; Neves, B. J.; Cravo, P. V. L.; Barreto, F. S.; Filho, M. O. M.; Perez, C. N.; Napolitano, H. B.; New J. Chem. 2018, 42, 3426.

11. Rampa, A.; Montanari, S.; Pruccoli, L.; Bartolini, M.; Falchi, F.; Feoli, A.; Cavalli, A.; Belluti, F.; Gobbi, S.; Tarozzi, A.; Future Med. Chem. 2017, 9, 749.

12. Zhang, X.; Rakesh, K. P.; Bukhari, S. N. A.; Balakrishna, M.; Manukumar, H. M.; Qin, H. L.; Bioorg. Chem. 2018, 80, 86.

13. Sivakumar, P. M.; Prabhawathi, V.; Doble, M.; SAR QSAR Environ. Res. 2010, 21, 247.

14. Rybka, M.; Mercader, A. G.; Castro, E. A.; Chemom. Intell. Lab. Syst. 2014, 132, 18.

15. Iman, M.; Davood, A.; Banarouei, N.; Turk. J. Chem. 2014, 38, 716.

16. Damazio, R. G.; Zanatta, A. P.; Cazarolli, L. H.; Mascarello, A.; Chiaradia, L. D.; Nunes, R. J.; Yunes, R. A.; Silva, F. R. M. B.; Biochimie 2009, 91, 1493.

17. Begum, N. A.; Roy, N.; Laskar, R. A.; Roy, K.; Med. Chem. Res. 2011, 20, 184.

18. Kang, J. E.; Cho, J. K.; Curtis-Long, M. J.; Ryu, H. W.; Kim, J. H.; Kim, H. J.; Yuk, H. J.; Kim, D. W.; Park, K. H.; Molecules 2013, 18, 140.

19. Carregal, A. P.; Maciel, F. V.; Carregal, J. B.; Santos, B. R.; da Silva, A. M.; Taranto, A. G.; J. Mol. Model. 2017, 23, DOI: 10.1007/s00894-017-3253-8.

20. Lauro, G.; Romano, A.; Riccio, R.; Bifulco, G.; J. Nat. Prod. 2011, 74, 1401.

21. Westermaier, Y.; Barril, X.; Scapozza, L.; Methods 2015, 71, 44.

22. Low, J. N.; Cobo, J.; Nogueras, M.; Albornoz, A.; Abonia, R.; Acta Crystallogr., Sect. C: Cryst. Struct. Commun. 2002, 1, 42.

23. Bandgar, B. P.; Gawande, S. S.; Bodade, R. G.; Totre, J. V.; Khobragade, C. N.; Bioorg. Med. Chem. 2010, 18, 1364.

24. SHELXTL-NT; Bruker AXS GMBH: Karlsruhe, Germany, 2002.

25. Groom, C. R.; Bruno, I. J.; Lightfoot, M. P.; Ward, S. C.; Acta Crystallogr., Sect. B Struct. Sci., Cryst. Eng. Mater. 2016, 72, 171.

26. Spackman, M. A.; Jayatilaka, D.; CrystEngComm 2009, 11, 19.

27. McKinnon, J. J.; Spackman, M. A.; Mitchell, A. S.; Acta Crystallogr., Sect. B Struct. Sci., Cryst. Eng. Mater. 2004, 60, 627.

28. Hirshfeld, F. L.; Theor. Chim. Acta 1977, 44, 129.

29. Mckinnon, J. J.; Mitchell, A. S.; Spackman, M. A.; Chem. Commun. 1998, 2071. 
30. McKinnon, J. J.; Jayatilaka, D.; Spackman, M. A.; Chem. Commun. 2007, 37, 3814.

31. Spackman, M. A.; McKinnon, J. J.; CrystEngComm 2002, 4, 378.

32. Frisch, M. J.; Trucks, G. W.; Schlegel, H. B.; Scuseria, G. E.; Robb, M. A.; Cheeseman, J. R.; Scalmani, G.; Barone, V.; Mennucci, B.; Petersson, G. A.; Nakatsuji, H.; Caricato, M.; Li, X.; Hratchian, H. P.; Izmaylov, A. F.; Bloino, J.; Zheng, G.; Sonnenberg, J. L.; Hada, M.; Ehara, M.; Toyota, K.; Fukuda, R.; Hasegawa, J.; Ishida, M.; Nakajima, T.; Honda, Y.; Kitao, O.; Nakai, H.; Vreven, T.; Montgomery Jr., J. A.; Peralta, J. E.; Ogliaro, F.; Bearpark, M.; Heyd, J. J.; Brothers, E.; Kudin, K. N.; Staroverov, V. N.; Kobayashi, R.; Normand, J.; Raghavachari, K.; Rendell, A.; Burant, J. C.; Iyengar, S. S.; Tomasi, J.; Cossi, M.; Rega, N.; Millam, N. J.; Klene, M.; Knox, J. E.; Cross, J. B.; Bakken, V.; Adamo, C.; Jaramillo, J.; Gomperts, R.; Stratmann, R. E.; Yazyev, O.; Austin, A. J.; Cammi, R.; Pomelli, C.; Ochterski, J. W.; Martin, R. L.; Morokuma, K.; Zakrzewski, V. G.; Voth, G. A.; Salvador, P.; Dannenberg, J. J.; Dapprich, S.; Daniels, A. D.; Farkas, Ö.; Foresman, J. B.; Ortiz, J. V.; Cioslowski, J.; Fox, D. J.; Gaussian 09, Revision D.01; Gaussian Inc., Wallingford, CT, USA, 2009.

33. Zhao, Y.; Truhlar, D. G.; Theor. Chem. Acc. 2008, 120, 215.

34. Krishnan, R.; Binkley, J. S.; Seeger, R.; Pople, J. A.; J. Chem. Phys. 1980, 72, 650.

35. McLean, A. D.; Chandler, G. S.; J. Chem. Phys. 1980, 72, 5639.

36. Hohenstein, E. G.; Chill, S. T.; Sherrill, C. D.; J. Chem. Theory Comput. 2008, 4, 1996.

37. Pereira, D. H.; la Porta, F. A.; Santiago, R. T.; Garcia, D. R.; Ramalho, T. C.; Rev. Virtual Quim. 2016, 8, 425.

38. Yoshida, M.; Aihara, J.; Phys. Chem. Chem. Phys. 1999, 1, 227.

39. Galabov, B.; Nikolova, V.; Ilieva, S.; Chem. - Eur. J. 2013, 19, 5149.

40. Sjoberg, P.; Politzer, P.; J. Phys. Chem. 1990, 94, 3959.
41. Liu, X.; Ouyang, S.; Yu, B.; Liu, Y.; Huang, K.; Gong, J.; Zheng, S.; Li, Z.; Li, H.; Jiang, H.; Nucleic Acids Res. 2010 , 38,5 .

42. Mancini, F.; de Simone, A.; Andrisano, V.; Anal. Bioanal. Chem. 2011, 400, 1979.

43. Berman, H. M.; Westbrook, J.; Feng, Z.; Gilliland, G.; Bhat, T. N.; Weissig, H.; Shindyalov, I. N.; Bourne, P. E.; Nucleic Acids Res. 2000, 28, 235.

44. Binkowski, T. A.; Naghibzadeh, S.; Liang, J.; Nucleic Acids Res. 2003, 31, 3352.

45. Pettersen, E. F.; Goddard, T. D.; Huang, C. C.; Couch, G. S.; Greenblatt, D. M.; Meng, E. C.; J. Comput. Chem. 2004, 25, 1605.

46. Simmerling, C.; J. Chem. Theory Comput. 2015, 31, DOI: 10.1021/acs.jctc.5b00255.

47. Trott, O.; Olson, A. J.; J. Comput. Chem. 2009, 31, DOI: $10.1002 /$ jcc. 21334.

48. Sklenar, H.; Jäger, J.; J. Quantum Chem. 1979, 16, 467.

49. Arroio, A.; Honório, K. M.; da Silva, A. B. F.; Quim. Nova 2010, 33, 694.

50. Congreve, M.; Aharony, D.; Albert, J.; Callaghan, O.; Campbell, J.; Carr, R. A. E.; Chessari, G.; Cowan, S.; Edwards, P. D.; Frederickson, M.; J. Med. Chem. 2007, 50, 1124.

51. Friesner, R. A.; Banks, J. L.; Murphy, R. B.; Halgren, T. A.; Klicic, J. J.; Mainz, D. T.; Repasky, M. P.; Knoll, E. H.; Shelley, M.; Perry, J. K.; J. Med. Chem. 2004, 47, 1739.

52. Kramer, B.; Rarey, M.; Lengauer, T.; Proteins 1999, 37, 228.

53. Patel, S.; Vuillard, L.; Cleasby, A.; Murray, C. W.; Yon, J.; J. Mol. Biol. 2004, 343, 407.

54. Hong, L.; Tang, J.; Biochemistry 2004, 43, 4689.

Submitted: November 26, 2018

Published online: May 21, 2019 